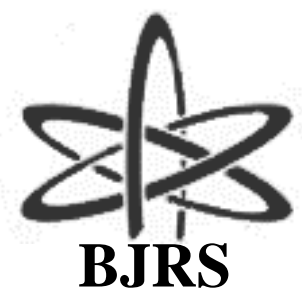

BRAZILIAN JOURNAL

$\mathrm{OF}$

RADIATION SCIENCES

08-03A (2020) 01-18

\title{
New advances in the computational simulation of Aqueous Homogeneous Reactor for medical isotopes production
}

\author{
Daniel Milian Pérez, Liván Hernández Pardo, Daylen Milian Pérez, Abel Gámez \\ Rodríguez, Daniel Evelio Milian Lorenzo, Carlos Alberto Brayner de Oliveira Lira \\ University of Havana \\ daniel.milian@ufpe.br
}

\begin{abstract}
Aqueous Homogeneous Reactors (AHRs) or simply solution reactors present nowadays a promising alternative to produce medical isotopes, especially ${ }^{99} \mathrm{Mo}$. The AHR medical production concept has been proposed to produce medical isotopes directly in the fuel solution, resulting in a potentially competitive alternative in comparison with the solid target irradiation method in heterogeneous reactors. Furthermore, the utilization of AHRs for medical isotopes production has been strengthened because of the successful operation of the ARGUS reactor since 1981 and its conversion to low-enriched uranium (LEU) fuel during 2012-2014. Those successes positively influenced in the decisions to construct a Proof-Of-Concept production site based on the ARGUS operational experience in Sarov (500 km from Moscow) and to restore the Argus-FTI at the Umarov Physical and Technical Institute in Dushanbe, Tajikistan. However, demonstrating the viability of the AHRs for medical isotopes requires solving several significant challenges related with the safe operation of these reactors. Consequently, not only for the design, licensing and safe operation of the AHRs, but also for the prediction of accident scenarios it is very important to be able to simulate and predict the behavior of the fuel solutions through a group of relevant physical parameters. Accordingly, this paper aims to show the advances made to improve the predictive capabilities during the multi-physics computational modeling of AHRs.
\end{abstract}

Keywords: Aqueous Homogeneous Reactor, Radioisotope production, ${ }^{99} \mathrm{Mo}$, MCNP, ANSYS-CFX. 


\section{INTRODUCTION}

Although the AHRs mainly exist today as experimental and demonstrative facilities, with only two operational AHR at the beginning of 2020, the growing recognition of their unique characteristics makes them leading candidates for the present and future radioisotopes production, especially the ${ }^{99}$ Mo production [1,2]. Compared with a multipurpose research reactor, an AHR dedicated for ${ }^{99}$ Mo production has advantages such as (1) flexibility in operating power ranges according to the ${ }^{99}$ Mo demand, (2) high safety characteristics in terms of the large negative density coefficient of reactivity, (3) a reduction of ${ }^{235} \mathrm{U}$ requirement compared with the current research reactors, (4) a significant reduction of waste generation, (5) far simpler waste management, and (6) no need of costs related to the fabrication, transportation, irradiation, disassembly and dissolution of targets $[1,3-5]$.

In general, the fuel in the AHRs is a soluble salt dissolved in water and acid which is contained in a shielded tank or vessel. Mainly, three types of aqueous fuel solutions have been used: uranium nitrate $\left[\mathrm{UO}_{2}\left(\mathrm{NO}_{3}\right)_{2}\right]$, uranium sulphate $\left[\mathrm{UO}_{2} \mathrm{SO}_{4}\right]$, and uranium fluoride $\left[\mathrm{UO}_{2} \mathrm{~F}_{2}\right]$. The AHR technology was highly researched in the early years of the nuclear age, with more than 30 solution reactors built worldwide and operated over many years, accumulating over 149 years of combined experience. However, the formation of gas bubbles and problems regarding the suitability of materials discouraged development of the technology for electricity generation [6-8].

On the other hand, since 1981, operates at the Russian Research Centre "Kurchatov Institute" the ARGUS reactor (Fig. 1). The ARGUS constitutes the only large-scale experiment on the use of an AHR in steady-state operation (20 kWth - $1 \mathrm{kWth} / \mathrm{L}$ of solution). Studies carried out with ${ }^{99}$ Mo samples obtained from an irradiated uranium sulphate solution in the ARGUS reactor concluded that the ${ }^{99}$ Mo samples are radiochemically pure to European and US pharmacopeia standards [1]. The ARGUS reactor, initially working with highly enriched uranium (HEU), was converted to use low enriched uranium (LEU) fuel during 2010-2012, after positive results in the neutron-physical and thermal-hydraulic feasibility calculations $[9,10]$. In 2015, after taking in consideration the success in the ARGUS conversion to LEU, the State Atomic Energy Corporation ROSATOM decided to construct a Proof-Of-Concept production site based on solution reactor in Sarov (500 km 
from Moscow) with a production capacity 250 six-day Ci per week of ${ }^{99}$ Mo [11]. In addition, the Argus-FTI (at the Umarov Physical and Technical Institute in Dushanbe, Tajikistan) will be restored, to be operational in 2020, with Russian assistance under financial support of China [12].

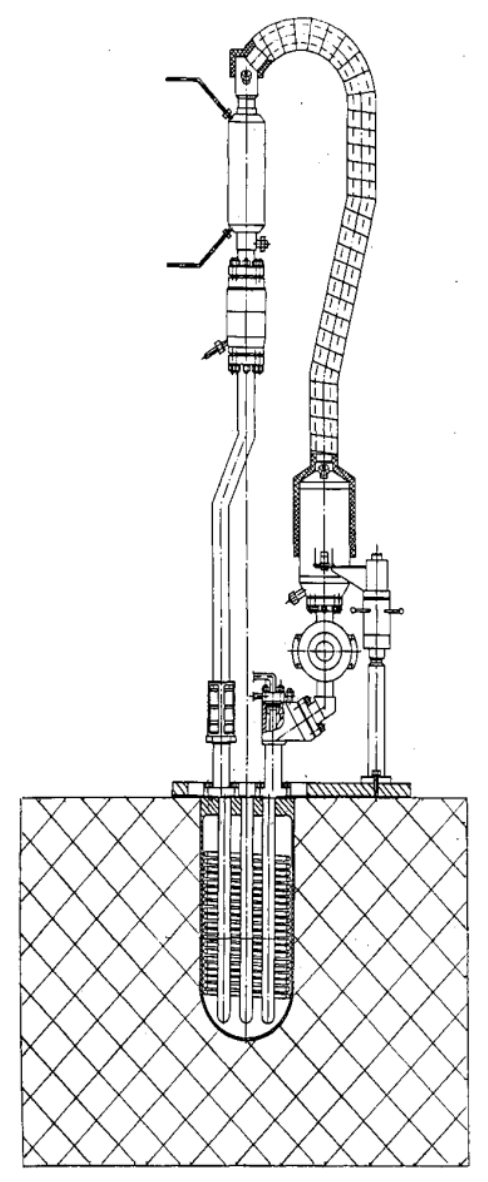

Figure 1: Scheme of the Russian ARGUS reactor.

Source: [9]

Although the renewed interest in the AHRs for the production of medical isotopes has led to the development of theoretical and experimental researches, summarized in several papers and technical reports, the predictive capabilities of the computational platforms and models developed are still limited. Which is a very important topic in demonstrating the viability of the AHRs for medical isotopes and solve a number of significant challenges related not only with the safe operation of these reactors, but also with the design, licensing and the prediction of accident scenarios. Consequently, a research group composed of researchers from the nuclear engineering 
departments of the UFPE and UH has been working in the modeling, simulation, and behavior prediction of fuel solutions, through relevant physical parameters, since 2014. This paper aims to show the advances made in these seven years to improve that predictive capabilities during the multi-physics computational modeling of AHRs.

\section{MATERIALS AND METHODS}

\subsection{Computational platform}

The multi-physics calculations have been carried out using two computational clusters. The InSTEC-IRL cluster (operating system: Microsoft Windows 64 bit, 48 cores and 96 GB Memory) and the UFPE-DEN-GER cluster (operating system: Microsoft Windows 64 bit, 64 cores and 152 GB Memory). The available computational codes system, used in the multi-physics modeling, simulation and behavior prediction of fuel solutions, is composed mainly by two codes, the MCNP (for the neutronic calculations) and the ANSYS-CFX (for the thermal-hydraulic assessment). Additional (home-made) codes have been developed for the pre-processing and post-processing of the main codes.

MCNP is a general-purpose Monte Carlo N-Particle code that can be used for neutron, photon, electron or coupled neutron/photon/electron transport. Specific areas of application include, but are not limited to, radiation protection and dosimetry, radiation shielding, radiography, medical physics, nuclear criticality safety, detector design and analysis, nuclear oil well logging, accelerator target design, fission and fusion reactor design, decontamination and decommissioning. MCNP in its latest versions included a group of new capabilities and enhancements beyond its predecessors used in this study such as the depletion/burnup capability and the superimposed mesh tally (FMESH) card [13]. ANSYS-CFX is a general purpose CFD software suite that combines an advanced solver with powerful pre-processing and post-processing capabilities for the design, analysis, and simulation of systems involving fluid flow, heat transfer, and other related physical processes. Working with ANSYS-CFX module includes a set of steps such as, creating geometry, generating meshes, preparing the calculation, executing the solvers and post-processing the results. It works by solving the equations of fluid flow (in a special form) over a region of interest, with specified initial 
and boundary conditions of that region. Methods of CFD assume computation of liquid and gas flows by numerical solution of Navier-Stokes and continuity equations (for turbulent flows, Reynolds equations) which describe the most general case of movement of fluid medium [14].

\subsection{Developed computational models}

Several computational models of AHRs have been developed for neutronic and thermalhydraulic calculations, such as the HEU and LEU ARGUS, the SUPO reactor and others. Based in the experience gained is that tasks, an ARGUS based conceptual design have been developed and studied, the results of such studies have been already published [4,15-17].

The geometrical AHR conceptual design developed (based on the ARGUS reactor LEU configuration) [9,10,18] (Fig. 2) consists of an aqueous uranyl sulfate solution located in a steel cylindrical vessel with a hemispherical bottom. Core vessel wall thicknesses used was $0.5 \mathrm{~cm}$. Placed inside the vessel, there are a coiled-tube heat exchanger, one central channel and two symmetric peripheral channels. The central channel has an experimental purpose, while the other two channels are intended for control rods. The steel channels are $4.8 \mathrm{~cm}$ in outer diameter, and their wall thickness is $0.2 \mathrm{~cm}$. The reactor vessel is surrounded with side and bottom graphite reflectors. An aqueous solution of uranyl sulfate $\left(\mathrm{UO}_{2} \mathrm{SO}_{4}\right)$ enriched in ${ }^{235} \mathrm{U}$ to $19.8 \%$ is used as the fissile material. The atomic densities of the aqueous solution of uranyl sulfate were calculated using the methodology presented in [18]. The fuel solution height and therefore the fuel solution volume were selected to guarantee at least a reactivity reserve of $4 \beta_{\text {eff }}[10]$. The uranium concentration is $390 \mathrm{~g} / \mathrm{liter}$, and the fuel solution height is $40.39 \mathrm{~cm}$, giving a fuel solution volume of $22.65 \mathrm{~L}$ (these values were calculated at $20{ }^{\circ} \mathrm{C}$ and without considering the production of radiolytic gas bubbles in the fuel solution). The amount of ${ }^{235} \mathrm{U}$ in the whole reactor is $1.63 \mathrm{~kg}$. The planned power density is $0.88 \mathrm{kWth} /$ liter of solution, and the operating temperature of the uranium solution is less than 90 ${ }^{\circ} \mathrm{C}$. The internal coiled-tube heat exchanger uses at about $19 \mathrm{~m}$ of stainless-steel tubing, $0.60 \mathrm{~cm}$ inner diameter and $1.0 \mathrm{~cm}$ outer diameter. Inside the coiled-tube heat exchanger flows distilled water as refrigerant, with a mass flow rate of $0.3 \mathrm{~m}^{3} / \mathrm{h}$ and inlet temperature of $25^{\circ} \mathrm{C}$. Improvements to the heat removal system of that geometrical AHR conceptual design have been made to take into consideration increases in thermal power $(50 \mathrm{kWth}$ and $75 \mathrm{kWth})$. The improvements in the heat 
removal system included modifications in the refrigerant mass flow rate and inlet temperature and using up to five coiled cooling pipes.
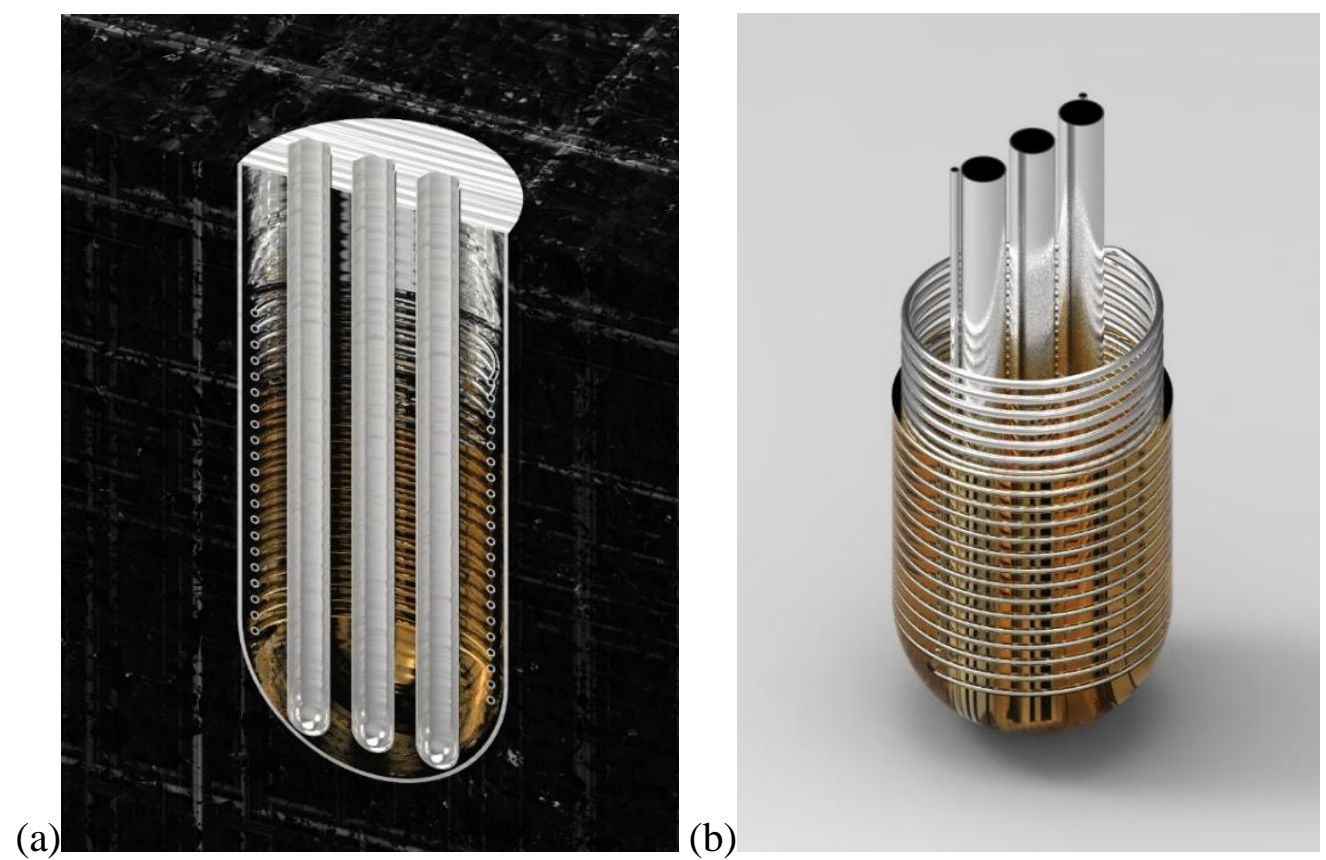

Figure 2: AHR conceptual design model with one coiled cooling pipe. (a) Longitudinal section of the assembly core. (b) View of vessel's internal parts including the core channels, the coiled cooling pipe, and the fuel solution.

Source: [17]

A distinctive characteristic of the AHRs is the generation of gas in the fuel solution due to the radiolysis of water. In this process are produced hydrogen, oxygen and others through the energy deposited through fission fragments. The radius of the radiolytic gas bubbles following their nucleation grows or shrinks depending on the concentration of hydrogen and oxygen in the solution. The formation of these bubbles creates a void volume in the fuel solution that introduces a negative coefficient of reactivity, resulting in a power reduction and power fluctuations with the migration and eventual escape of the bubbles from the fuel solution. Therefore, the production of medical isotopes with solution reactors may not be accomplished without mitigation of the effects produced by radiolytic-gas bubble formation [19]. The model more used globally for the calculation of the total volume of radiolytic-gas bubbles produced in the fuel solution was proposed by Souto et al, 2005 [19]. Several modification or improvements to this model have been proposed by [20]. For the 
determination of the mature bubble size, was used a linear relationship developed by [21] using experimental values from [22-24].

Figs. 3 and 4 show the geometrical model of the AHR conceptual design on the MCNP Visual Editor, Fig. 5 shows the same model including the explicit representation of the radiolytic gas bubbles [17]. Fig. 6 shows the geometrical model of the AHR conceptual design in the ANSYS DesignModeler module $[4,16]$. The main reactor core parameters are shown in Table 1.

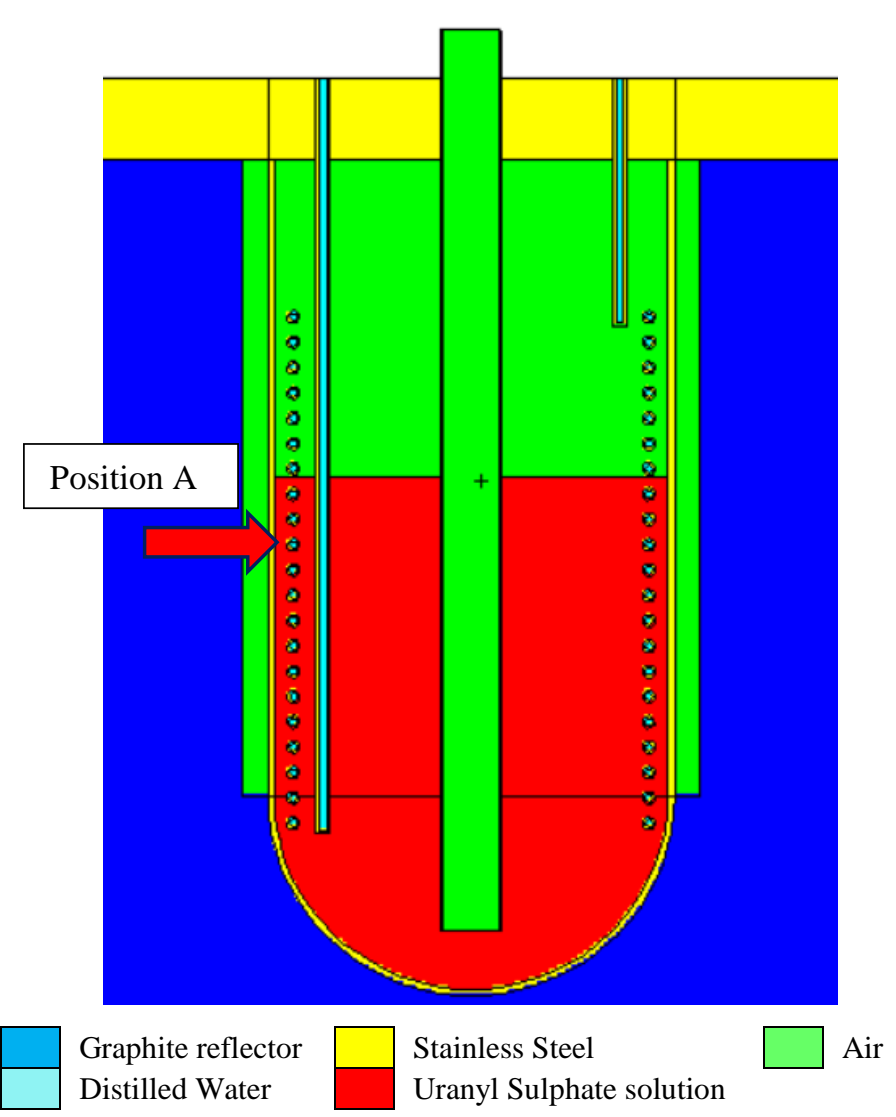

Figure 3: Longitudinal section of the geometrical model of the reactor.

Source: [17] 


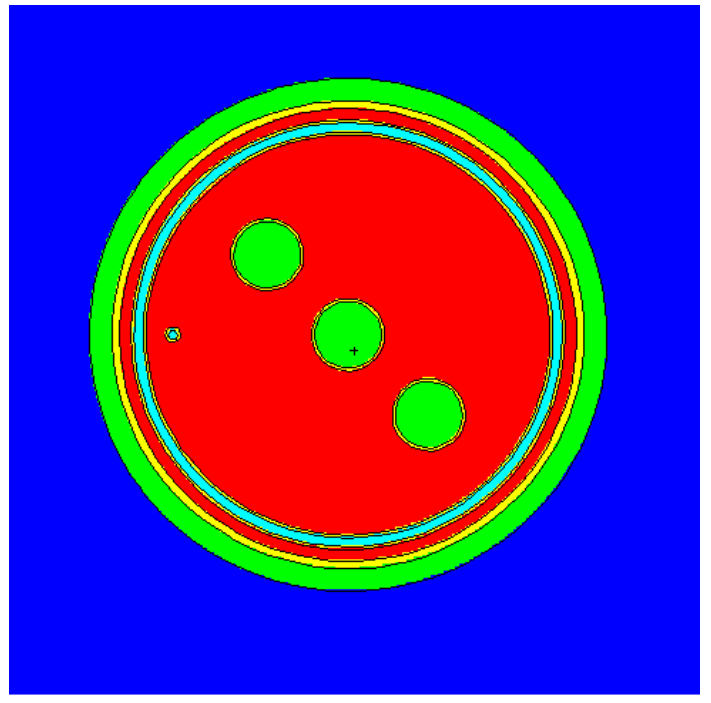

Graphite reflector Distilled Water

Stainless Steel Air Uranyl Sulphate solution

Figure 4: Cross section of the geometrical model of the reactor (in position A). Source: [17]

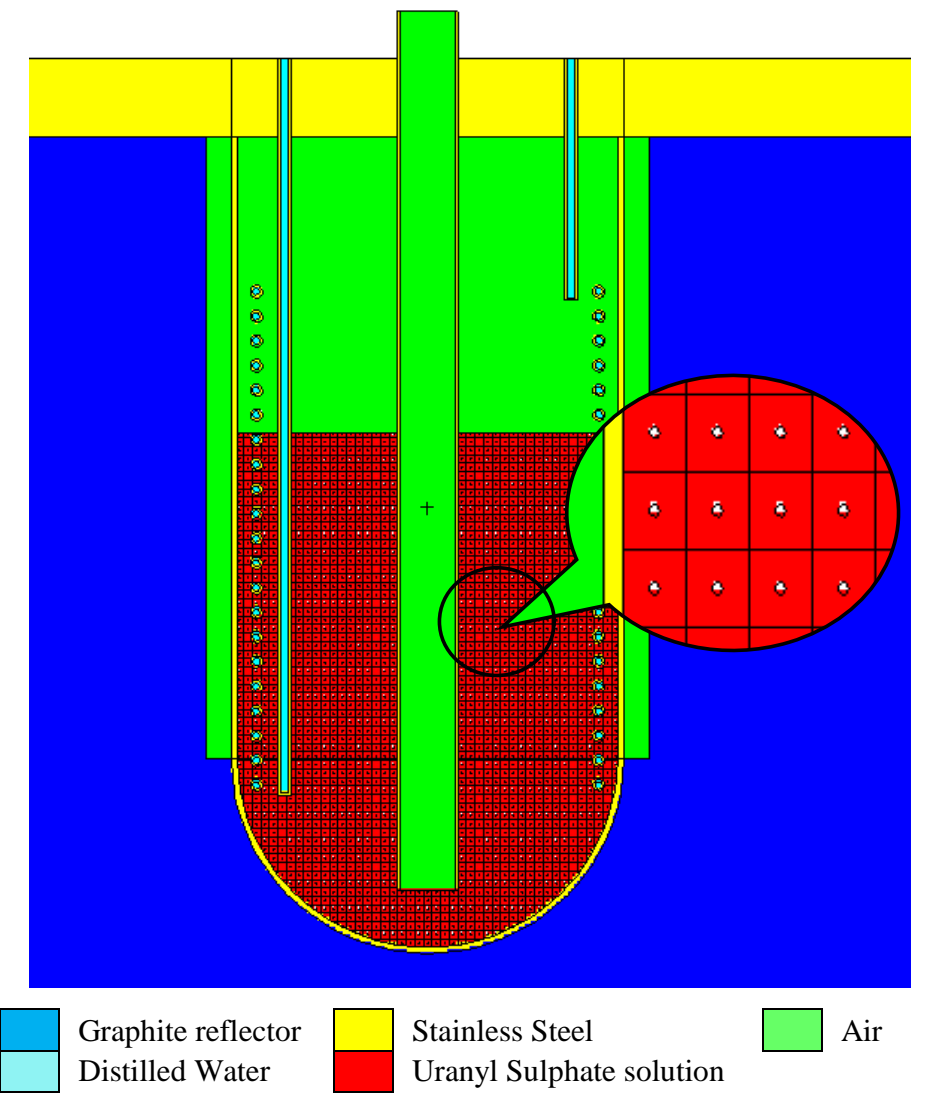

Figure 5: Uniform distribution of radiolytic-gas bubbles using a repetitive structure of spheres. Source: [17] 


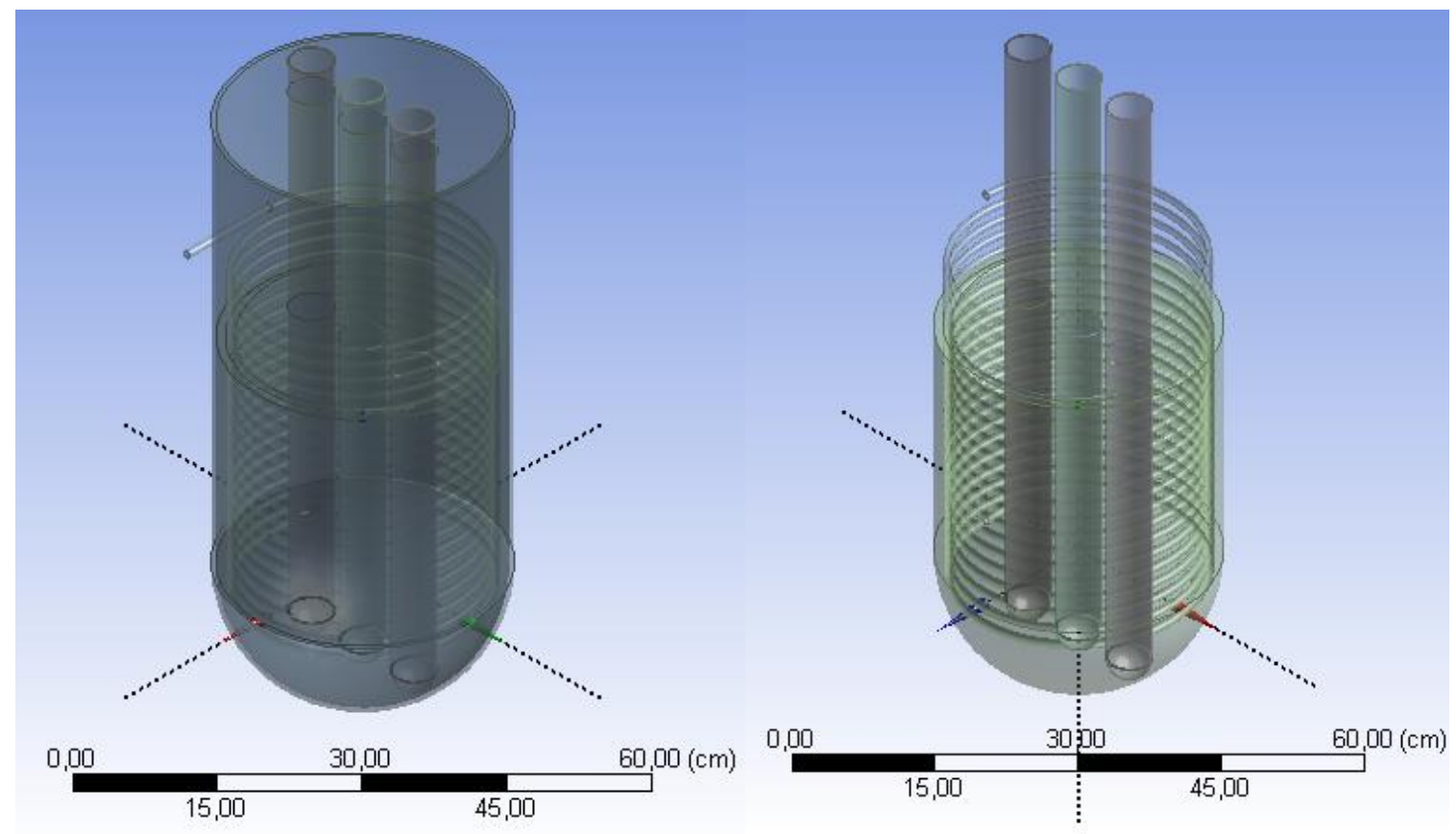

Figure 6: AHR conceptual design in the ANSYS DesignModeler module. Source: $[4,16]$

Table 1: The main reactor core parameters.

\begin{tabular}{cc}
\hline Parameter & Value \\
\hline Fuel solution & Uranyl sulfate solution \\
Uranium concentration $(\mathrm{g} / \mathrm{liter})$ & 390 \\
Inner core diameter $(\mathrm{cm})$ & 30.5 \\
Reactor height $(\mathrm{cm})$ & 65.6 \\
Reactor vessel & Stainless steel \\
Vessel thickness $(\mathrm{cm})$ & 0.5 \\
Reflector (radial) & Graphite $-60 \mathrm{~cm}$ \\
Solution Density $\left(\mathrm{g} / \mathrm{cm}^{3}\right)$ & 1.5059 \\
Thermal Power $(\mathrm{kWth})$ & 20 \\
Cold solution volume with no voids (liter) & 22.65 \\
Power density (kWth/liter of solution) & $\sim 0.88$ \\
\hline
\end{tabular}

\subsection{Benchmarking exercises}

Several benchmarking exercises have been carried out, that exercises include neutronic and thermal-hydraulic studies of two solution reactors, the SUPO and ARGUS reactors. The first benchmarking exercise was performed using available results of four critical experiments performed at the Russian Research Center "Kurchatov Institute" [18] in order to validate that the 
developed models of AHR with MCNP and ANSYS-CFX are adequate for studies of aqueous fuel solutions. In the second benchmarking exercise, the geometrical and material configuration of the SUPO reactor was modeled in ANSYS-CFX and the results of the calculation compared with those available in the scientific literature [22,25]. The results obtained during these benchmarking exercises have been published and comprehensively discussed in [4,15-17]. In all cases, the calculations results obtained are in good agreement with the experimental results. So, it can be concluded that the developed models are able to acceptably predict the neutronic and thermalhydraulics behavior of an AHR.

\section{RESULTS AND DISCUSSION}

Some of the main tasks carried out for the multi-physics modeling and simulation of AHRs, in these seven years, are the following:

(1) Perform benchmarking exercises using available results of critical experiments carried out at the Russian Research Center "Kurchatov Institute" in 1980-1981 and the SUPO reactor.

(2) Evaluate the effects of some calculation parameters on the computational modelling of temperature, velocity, and gas volume fraction during steady-state operation of an AHR.

(3) Calculate parameters related to the neutronic (such as critical height, medical isotopes production, uranium consumption, plutonium production) and thermo-hydraulic (such as fuel solution temperature and velocity, gas bubbles velocity and volume fraction) behavior of the core of a 20 kWth AHR conceptual design.

(4) Redesign and improvement of the AHR conceptual design to operate to $75 \mathrm{~kW}$ th to produce more medical isotopes activity.

(5) Evaluate the reactivity feedback introduced in the solution by the volumetric expansion of the fuel solution due to thermal expansion of the fuel solution and the void volume generated by radiolytic gas bubbles.

(6) Determination of kinetic parameters of the AHR conceptual design such as the effective delayed neutron fraction, $\beta$ eff, mean neutron generation time, $\Delta$ and the $\beta \mathrm{eff} / \Delta$ ratio. 
(7) Perform coupled multi-physics calculations of a $50 \mathrm{kWth}$ AHR conceptual design for producing ${ }^{99}$ Mo to meet the domestic demand of Brazil using a computational coupling methodology.

The results obtained in those tasks have been comprehensively explained in several papers along these years. Pérez et al., 2015 focused on the thermal-hydraulics study of the core of a 20 and $75 \mathrm{~kW}$ th AHR based on the ARGUS reactor LEU configuration using ANSYS-CFX 14 code and an AHR model consisting of the vessel, the core channels, the coiled cooling pipe, the fuel solution, and the upper air zone. The main objective of the thermal-hydraulics study was evaluating the heat removal systems to show that sufficient cooling capacity exists to prevent fuel solution overheating. Was determined that the ARGUS based heat removal systems, designed for working at $20 \mathrm{kWth}$, are not able to provide sufficient cooling capacity to prevent fuel solution overheating after increasing the thermal power to $75 \mathrm{kWth}$. To solve this problem, the conceptual design was improved, increasing the number of coiled cooling pipes inside the core from one to five [4]. Pérez et al., 2017 focused on the improvement of the AHR conceptual design thermal-hydraulic model in ANSYS-CFX 14. For this purpose, six meshes, five time step size, three different models for solving flow problems (the laminar, k-epsilon, and SST), three numerical advection schemes (Upwind, High Resolution and SBF) and the available transient schemes (first- and second-order backward Euler) were evaluated in the simulations, in order to assess the effects of the calculation parameters: mesh refinement, time step size, turbulence models, transient schemes and numerical advection scheme on the computational modelling of key parameters of an AHR steady-state operation [16]. Milian et al., 2017 focused on the validation efforts with benchmarking exercises that include neutronic and thermal-hydraulic results of two solution reactors, the SUPO and ARGUS reactors. In addition, neutronic and thermal-hydraulic results of a $75 \mathrm{kWth}$ AHR based on the ARGUS reactor LEU configuration were presented and discussed [15]. Pérez et al., 2019 focused on the evaluation of relevant physical parameters of the AHR conceptual design such as the critical height, medical isotopes production, uranium consumption, plutonium production, the reactivity feedback introduced in the solution by the volumetric expansion of the fuel solution and the kinetic parameters effective delayed neutron fraction and mean neutron generation time. A benchmarking exercise was carried out to confirm that the developed models can acceptably predict the neutronic behavior of an AHR [17]. 
Fig. 7 shows the comparison between the $20 \mathrm{kWth}, 50 \mathrm{kWth}$ and $75 \mathrm{kWth}$ AHR conceptual design regarding the ${ }^{99}$ Mo saturation curve during the first 528 hours of reactor operation. As can be seen, the $75 \mathrm{kWth}$ AHR conceptual design produces more activity than the others conceptual designs. The reactor operation period chosen is five days (120 hours) as it keeps the net rate of ${ }^{99}$ Mo production high - as evidenced by Fig. 7 (the first five days see a steep, almost constant increase in activity). The calculated production of ${ }^{99}$ Mo using MCNP for the $20 \mathrm{kWth}$ model is 99 six-day $\mathrm{Ci}$, for the $50 \mathrm{~kW}$ th model is $246.5 \mathrm{six}$-day $\mathrm{Ci}$, while for the $75 \mathrm{kWth}$ model is 370 six-day Ci. Taking into consideration that the estimated Brazilian demand of ${ }^{99}$ Mo for 2025 is around 700 six-day $\mathrm{Ci}$ per week, then two $75 \mathrm{~kW}$ th AHR, three $50 \mathrm{~kW}$ th AHR or ten $20 \mathrm{~kW}$ th AHR could be used to meet the domestic demand of Brazil [26].

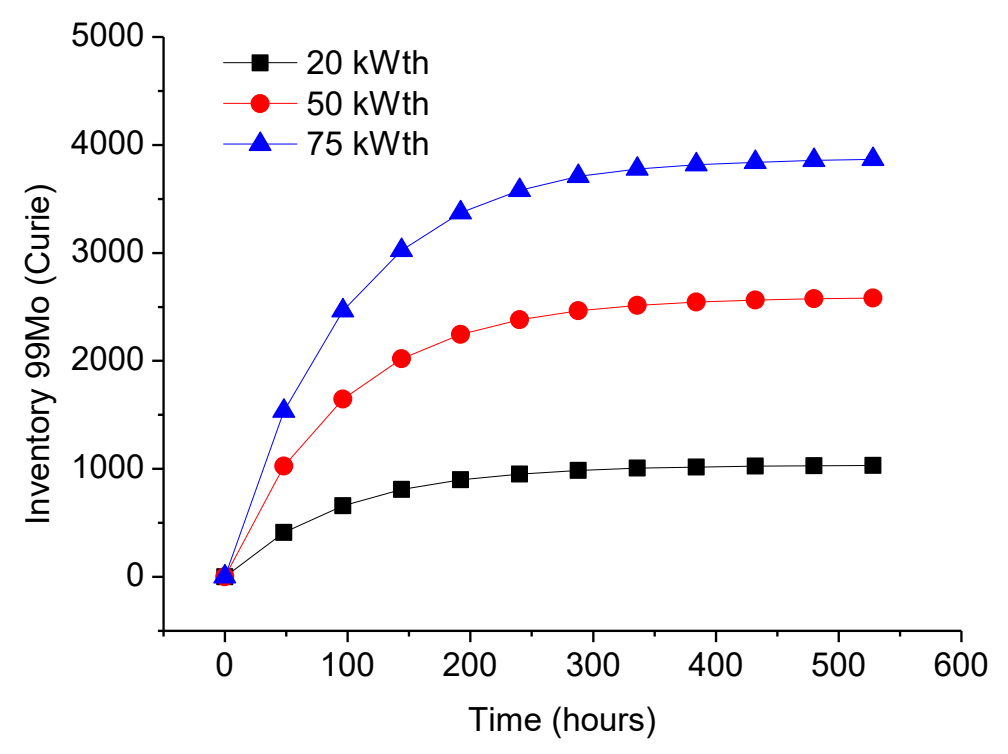

Figure 7: Accumulation of ${ }^{99}$ Mo for 528 hours of reactor operation.

Source: $[15,17,26]$

Fig. 8 shows the calculated accumulation of others medical isotopes using MCNP for the 20 $\mathrm{kW}$ th, $50 \mathrm{kWth}$ and $75 \mathrm{kWth}$ AHR conceptual design. As in the previous result, the $75 \mathrm{kWth}$ conceptual design produces more concentration of medical isotopes than the others do. 

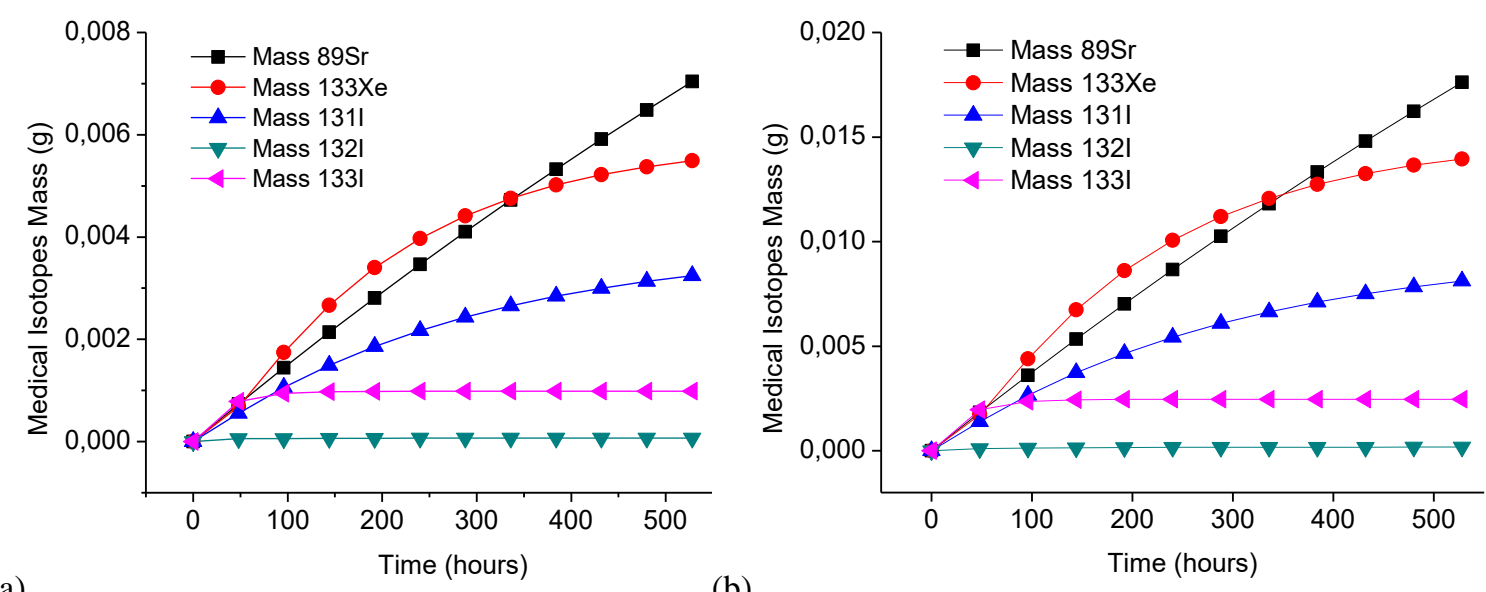

(a)

(b)

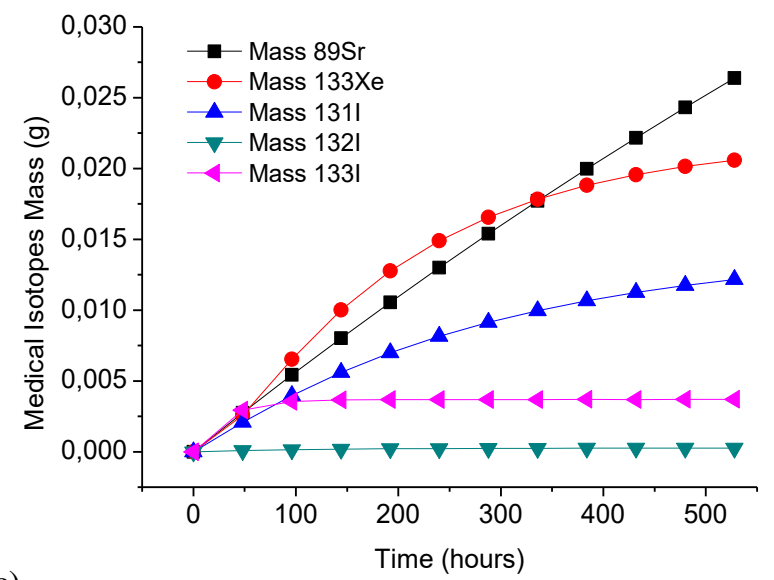

(c)

Figure 8: Accumulation of ${ }^{89} \mathrm{Sr},{ }^{133} \mathrm{Xe},{ }^{131} \mathrm{I},{ }^{132} \mathrm{I}$, and ${ }^{133} \mathrm{I}$ for 528 hours of reactor operation (a) 20 kWth, (b) $50 \mathrm{kWth}$ and (c) $75 \mathrm{kWth}$.

Source: $[15,17,26]$

Finally, Fig. 9 shows the volumetric temperature distribution in the fuel solution of the $20 \mathrm{kWth}$ (with one coiled cooling pipe), $50 \mathrm{kWth}$ (with two coiled cooling pipes, refrigerant mass flow rate of $1 \mathrm{~m}^{3} / \mathrm{h}$ and inlet temperature of $10{ }^{\circ} \mathrm{C}$ ) and $75 \mathrm{~kW}$ th (with five coiled cooling pipes) AHR conceptual designs. As can be seen, for the three models, the fuel solution temperature is below the design limit of temperature of $90{ }^{\circ} \mathrm{C}$. Average temperature in the three models are $75.15{ }^{\circ} \mathrm{C}, 70.83$ ${ }^{\circ} \mathrm{C}$ and $76.04{ }^{\circ} \mathrm{C}$, respectively. Therefore, it is proven that the heat removal systems have sufficient cooling capacity to prevent the fuel solution overheating. 

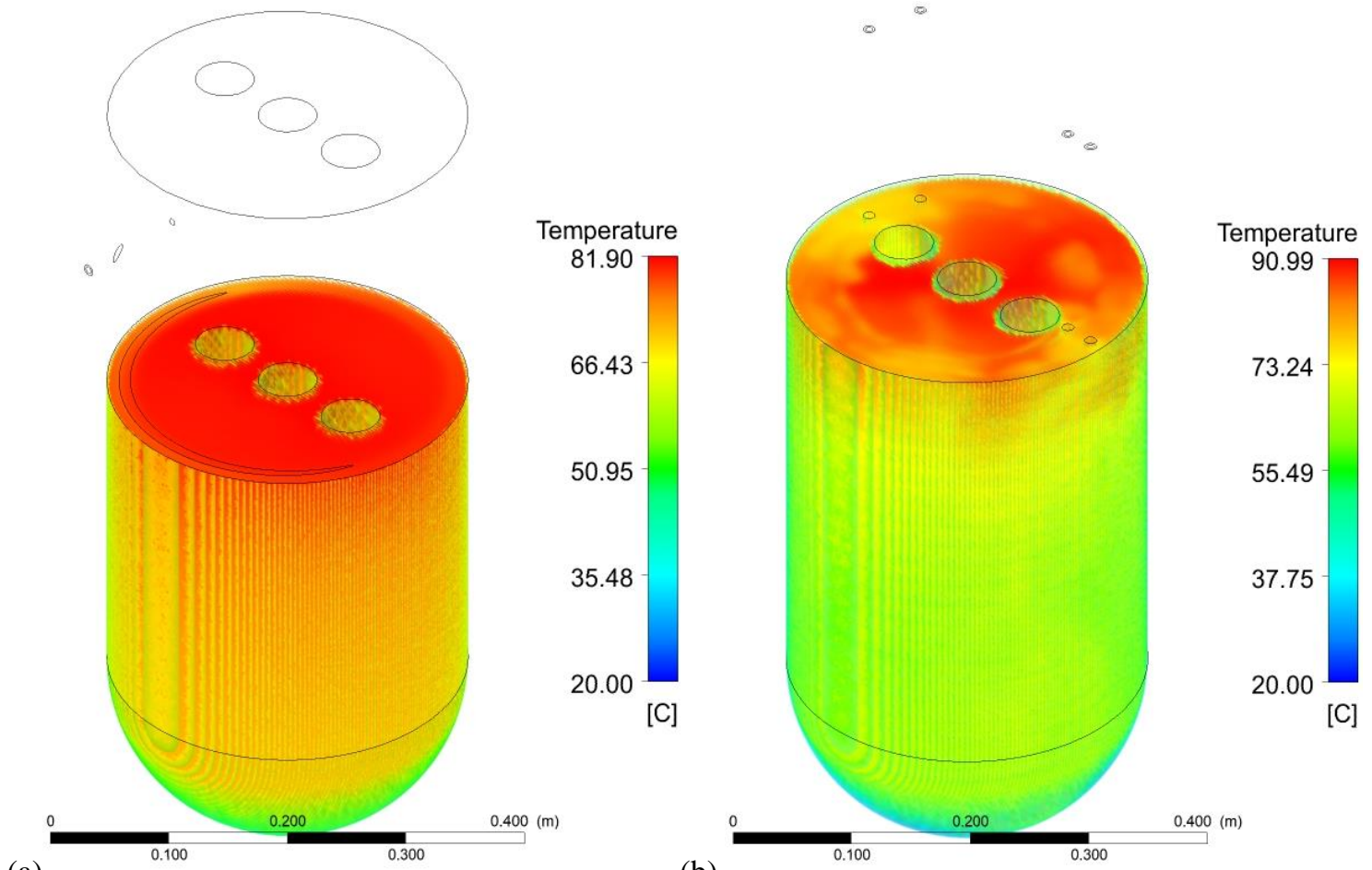

(a)

(b)

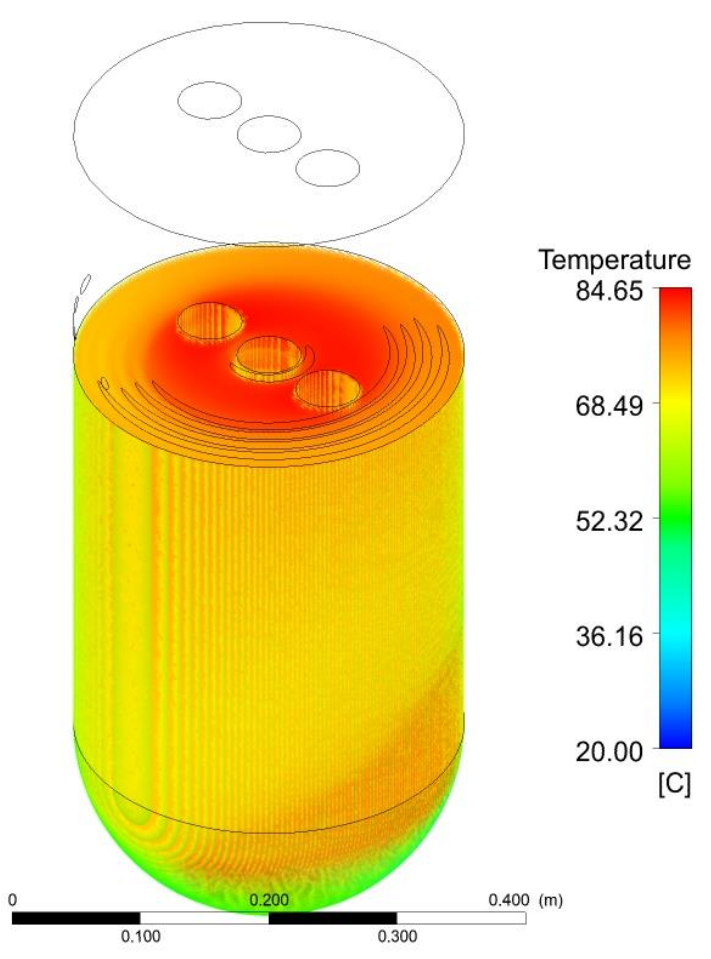

(c)

Figure 9: Temperature volume profile (a) $20 \mathrm{kWth}$, (b) $50 \mathrm{kWth}$ and (c) $75 \mathrm{kWth}$. Source: [15,26,27] 


\section{CONCLUSION}

The primary objective of this paper is contributing to the neutronic and thermal-hydraulic analysis of one of the most promissory alternatives to produce medical isotopes: the use of AHRs. This paper shows the advances made to improve the predictive capabilities during the multi-physics computational modeling of AHRs. Is discussed the current situation of the ARGUS based AHRs for medical isotope production and presented the available computational platform, composed by two computational clusters, acknowledged computational codes and home-made codes used for the multi-physics computational modeling. In addition, the computational models developed for the neutronic and thermal-hydraulic calculations are described, as well as the benchmarking exercises carried out to confirm that the developed models can acceptably predict the behavior of an AHR. Finally, some relevant results obtained for the three main AHR conceptual designs developed were discussed, as well as how those system could be used to meet the ${ }^{99}$ Mo domestic demand of Brazil.

The studies summarized in this paper contribute to demonstrate the feasibility of using AHRs to produce medical isotopes. However, a group of additional studies are still necessary to check that feasibility. Based on this need, studies are currently underway in order to assess the behavior of those systems under transient phenomena such as failure of the main heat removal system, cooling coils leak and mixture of the cooling water with the fuel solution, accidental insertion of positive reactivity and others. In addition, a coupled neutronic-thermohydraulic evaluation of a subcritical AHR conceptual design is being carried out. This new concept combines the strengths of accelerators and AHRs to minimize their drawbacks, mainly from the instability of the power level. 


\section{ACKNOWLEDGMENT}

This research was partially supported by the Conselho Nacional de Desenvolvimento Científico e Tecnológico (CNPq), project no: 141270/2016-0.

\section{REFERENCES}

[1] IAEA, "Homogeneous Aqueous Solution Nuclear Reactors for the Production of Mo-99 and other Short Lived Radioistotopes," Vienna, 2008.

[2] IAEA, "Research Reactor Database (RRDB)," 2020. [Online]. Available: https://nucleus.iaea.org/RRDB/RR/ReactorSearch.aspx?filter=0. [Accessed: 28-May-2020].

[3] IAEA, "Feasibility Of Producing Molybdenum-99 On A Small Scale Using Fission Of Low Enriched Uranium Or Neutron Activation Of Natural Molybdenum," Vienna, 2015.

[4] D. M. PEREZ et al., "Thermal-Hydraulics Study of a $75 \mathrm{~kW}$ th Aqueous Homogeneous Reactor for 99 Mo Production,” J. Thermodyn., vol. 2015, pp. 1-11, 2015.

[5] P. H. LIEM, H. N. TRAN, AND T. M. SEMBIRING, "Design optimization of a new homogeneous reactor for medical radioisotope Mo-99/Tc-99m production," Prog. Nucl. Energy, vol. 82, pp. 191-196, Jul. 2015.

[6] J. A. LANE, “Aqueous Homogeneous Reactors,” in Fluid Fuel Reactors, Oak Ridge, 1962, p. 30.

[7] A. J. YOUKER, S. D. CHEMERISOV, M. KALENSKY, P. TKAC, D. L. BOWERS, AND G. F. VANDEGRIFT, “A Solution-Based Approach for Mo-99 Production: Considerations for Nitrate versus Sulfate Media,”Sci. Technol. Nucl. Install., vol. 2013, pp. 1-10, 2013.

[8] IAEA, "Non-HEU Production Technologies for Molybdenum-99 and Technetium-99m," Vienna, 2013.

[9] S. V MYASNIKOV, A. K. PAVLOV, N. V PETRUNIN, AND V. A. PAVSHOOK, "Conversion of the ARGUS Solution Reactor to LEU Fuel: Results of Feasibility Studies and Schedule," in: RERTR 2012 - 34th International Meeting on Reduced Enrichment 
for Research and Test reactors, 2012, p. 8.

[10] P. P. BOldyReV, V. S. GOlubeV, S. V. MYASniKoV, A. K. PAVlov, N. V. PETRUNIN, AND V. A. PAVSHOOK, “The Russian ARGUS Solution Reactor HEU-LEU Conversion: LEU Fuel Preparation, Loading and First Criticality,” in: RERTR 2014 - 35th International Meeting on Reduced Enrichment for Research and Test reactors, 2014, p. 8.

[11] A. VAKULENKO, "ROSATOM's vision of Russia's role in global molybdenum-99 supply,"Vienna, 2017.

[12] IAEA, "Research Reactors: Purpose and Future," Vienna, 2010.

[13] LOS ALAMOS NATIONAL LABORATORY, "MCNP6.1/MCNP5/MCNPX User Manual.” Los Alamos National Laboratory, Los Alamos, p. 1001, 2013.

[14] ANSYS TEAM, “ANSYS CFD 19.0 Documentation, User's Guide manual,” 2019. [Online]. Available: http://www.ansys.com. [Accessed: 01-Jul-2019].

[15] D. M. PEREZ, D. E. M. LORENZO, C. A. BRAYNER, D. O. LIRA, AND L. P. R. GARCIA, "Neutronic And Thermal-Hydraulic Studies Of Aqueous Homogeneous Reactor For Medical Isotopes Production," in: International Nuclear Atlantic Conference - INAC 2017, 2017, vol. 99, p. 22.

[16] D. M. PEREZ, D. E. M. LORENZO, C. A. B. DE OllVEIRA LiRA, C. R. G. HERNANDEZ, M. C. RODRIGUEZ, AND L. P. R. GARCIA, "Effects of some calculation parameters on the computational modelling of temperature, velocity and gas volume fraction during steady-state operation of an aqueous homogeneous reactor,” Int. J. Nucl. Energy Sci. Technol., vol. 11, no. 1, p. 1, 2017.

[17] D. M. PEREZ, D. E. M. LORENZO, C. A. B. DE OliveIRA LIRA, AND L. P. R. GARCIA, "Neutronic evaluation of the steady-state operation of a $20 \mathrm{~kW}$ th Aqueous Homogeneous Reactor for Mo-99 production,” Ann. Nucl. Energy, vol. 128, 2019.

[18] E. S. GLOUCHKOV AND V. E. KHVOSTIONOV, "Graphite-reflected uranyl sulphate (20.9\% 235U) solutions," Moscow, 1997.

[19] F. J. SOUTO, R. H. KIMPLAND, AND A. S. HEGER, "Analysis of the Effects of Radiolytic-Gas Bubbles on the Operation of Solution Reactors for the Production of Medical Isotopes,” Nucl. Sci. Eng., vol. 150, no. 3, pp. 322-335, 2005. 
[20] C. M. COOLING, M. M. R. WILliamS, E. T. NYGAARD, AND M. D. EATON, “The application of polynomial chaos methods to a point kinetics model of MIPR: An Aqueous Homogeneous Reactor,” Nucl. Eng. Des., vol. 262, pp. 126-152, Sep. 2013.

[21] A. J. WASS, “Supo Thermal Model Development II,” Los Alamos, 2017.

[22] M. E. BUNKER, "Status Report on the Water Boiler Reactor," Los Alamos, 1963.

[23] S. CHEMERISOV et al., "Experimental Results For Direct Electron Irradiation Of A Uranyl Sulfate Solution: Bubble Formation And Thermal Hydraulics Studies," Argonne, 2015.

[24] L. D. P. KING, "Design and Description of Water Boiler Reactors," in: International Conference Peaceful Uses Atomic Energy, 1955, vol. 5, no. 32, pp. 372-391.

[25] A. G. BUCHAN et al., "Simulated transient dynamics and heat transfer characteristics of the water boiler nuclear reactor - SUPO - with cooling coil heat extraction," Ann. Nucl. Energy, vol. 48, pp. 68-83, Oct. 2012.

[26] D. M. PEREZ, "Projeto E Análise Neutrônico-Termoidráulica De Um Reator Homogêneo Aquoso Usando Combustível De Baixo Enriquecimento Para A Produção De Radioisótopos Usados Na Medicina,” Universidade Federal De Pernambuco, 2020.

[27] D. M. PEREZ, "Diseño conceptual de un AHR de 75 kWt que utiliza combustible LEU para la producción de isótopos médicos," Instituto Superior de Tecnologías y Ciencias Aplicadas, La Habana, 2015. 